\title{
Optimizing Adaptive Seating Solution in Case of Severely Disabled Cerebral Palsy Child
}

\author{
Swati Kurne ${ }^{1}$, Smita Jayavant ${ }^{2}$ \\ ${ }^{1}$ Occupational Therapist, All India Institute of Physical Medicine and Rehabilitation, Mumbai, Maharashtra, India \\ ${ }^{2}$ Head of Department - Occupational Therapy and Lecturer, All India Institute of Physical Medicine and Rehabilitation, Mumbai, \\ Maharashtra, India
}

\begin{abstract}
This case report describes the seating solutions in severe motor and cognitive developmental delay of a cerebral palsy child. Often children are prescribed commercially available seating devices which do not solve the problem in severely involved child. Here we demonstrate how an Occupational therapist working in a rehabilitation setting optimized seating device by custom made seating device components in modifying difficult posture in fully dependent child having very poor motor and cognitive function. Interdisciplinary team approach and individualized therapeutic seating program was effective in assisting the parents and child in meeting their positioning needs. The effectiveness of these seating solutions was assessed on parent questionnaire which showed improvement in positioning and social interaction.
\end{abstract}

Keywords: Optimum Seating, Severely Disabled, Cerebral Palsy

\section{Introduction}

Many children with cerebral palsy have difficulty or inability to sit independently due to moderate to severe impairment in motor and cognitive development. The severely multiply handicapped children require the knowledge and skills of Occupational Therapists to adapt the environment to individual needs. Adaptive seating may be the most important device available for any client who cannot be comfortably, safely and functionally seated in a commercially available wheelchair (Lynda 1985, Kathleen etal.2002; Janet Bower Hulme et al 1987).Evidence to date suggests that adaptive seating systems can play a major role in the positioning and support of children with disabilities such as cerebral palsy (Linda Mcnamara2005).

Seating solutions may require reaching a balance between an upright anatomical symmetrical posture and ability to function. Children with cerebral palsy will require external support from seating systems to accommodate for compromised postural control and postural deficits. The problems depicted in the literature commonly include retention of primitive reflexes, presence of structural asymmetries and abnormalities of muscle tone (Laura Neville 2005). To develop appropriate seating device an interdisciplinary rehabilitation team is extremely important. In our setting, therapist, orthotist, medical specialist, workshop skill worker worked in cooperation to design an individualized custom fabricated components of seating device. Assistive seating devices can include a range of components and it is essential that prescribing therapists understand their purpose and when they should be recommended (Linda Mcnamara.2005;Ling Sui Hui et al. 2011; J. Martin Carlson et al. 1987).

Here we present the case of a child with cerebral palsy with multiple handicapped having severe motor and cognitive delay. We discuss therapeutic success of the adapted seat and its effectiveness through parent questionnaire.

\section{Case Report}

A 5 1/2 year female child severely involved Cerebral palsy, GMFM level $\mathrm{V}$ with profound mental retardation with seizure disorder reported to AIIPMR for rehabilitation. Child had severe developmental delay in motor, cognitive, perceptual, emotional and social aspect.IQ test showed below 20 indicative of profound MR. On examination child was inactive, not playful with poor attention in the surroundings. There was moderate spasticity in bilateral upper and lower limbs. Primitive reflex ATNR was present abnormally. Poor control of bilateral upper and lower limbs, no purposeful movements with no motor milestones. Child had a Cerebral Palsy chair at home which did not support her posture adequately (fig 1) and parents express concern of poor posture in chair, carrying difficulty and need for outdoor mobility to socialize in her surroundings.

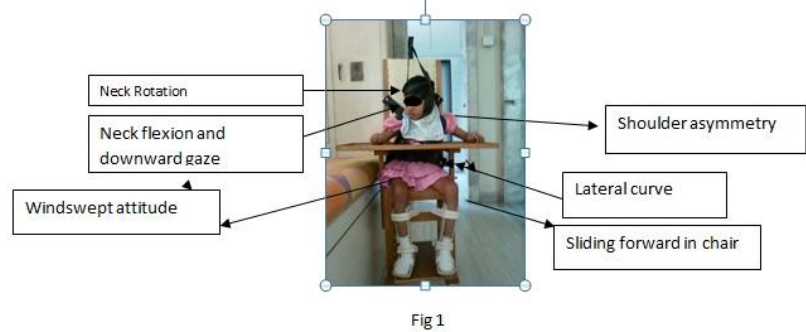

To achieve optimum seating position in wheelchair the case was discussed with medical specialist, orthotist and workshop skill worker for possible seating components in wheelchair such as, lateral trunk support, anterior wedge cushion and abductor wedge.

First ' $U$ ' shape head support of polythene material and orfit chin support were made to prevent anterior forward flexion. But head in midline and upright position was not achieved (fig 2).

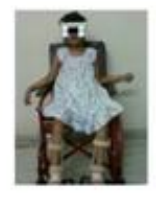




\section{International Journal of Science and Research (IJSR) \\ ISSN (Online): 2319-7064}

Index Copernicus Value (2015): 78.96 | Impact Factor (2015): 6.391

So total contact rigid cervical collar of orfit was decided to provide greater limitation for anterior flexion, lateral flexion and rotation. Anteriorly collar extended from bottom of chin to top of sternum and posteriorly occipital piece extending higher up. The collar prevented neck forward flexion but neck left lateral flexion, left neck rotation was not prevented with shoulder dropping on left side (fig 3 ).

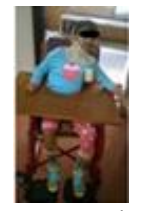

So collar was remolded as much as possible to maintain neck in neutral alignment. To prevent left lateral flexion niwar shoulder strap encircling axilla to pull shoulder up was attach on right side. Shoulders were at symmetrical level and well forward to be able to grasp objects with hands.(fig 4)

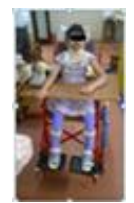

To control lateral curve lateral supports were placed one at the level of the apex of the scoliosis and the other just under the axilla on the opposite concave side in an arrangement referred to as the 3 point force system. Sliding in wheelchair was present so to prevent hips from coming forward; wedge height was increased from 2 inch to 3 inch. This helped to keep the hip from coming forward and kept hip at a better angle.

\section{Discussion}

Child had a better postural alignment when using the custom-made components of seating device as compared to the seating device used before intervention. Parent interview was taken after 4 months of use of wheelchair which provided feedback of effectiveness of such custom made individualized design of seating device. This case study reported beneficial effects of positioning including improved sitting balance, visual stimulation, social interaction and community acceptance. Through the questionnaire it indicated that positioning and social interaction improved but no change in eye hand activities. The average time spent sitting in seating device before receiving the equipment increased from two hrs to four hrs. Time spent lying down decreased from 8 to $10 \mathrm{hrs}$ to 6 to $8 \mathrm{hrs}$.

Client had difficult functional problem of flopping head or a head that pulls into flexion. The two designs of head support, polythene head support and orfit chin support did not resolve this problem. ATNR was very dominant with overriding abnormal tone and asymmetrical posture of head, trunk and extremities. By interdisciplinary team approach a comprehensive decision to fabricate rigid cervical collar of orfit was finalized. (Fig 4). It was effective in maintaining upright posture. It facilitated horizontal eye contact that encouraged visual orientation in the surrounding and increased social interaction. Head was kept close to midline to avoid active neck rotation. Herman and Lange (1999) suggest that the head should be kept close to midline to avoid active neck rotation which may elicit an ATNR. Head position can dictate overall body tone, particularly in the trunk and upper limbs / shoulder girdle. (Herman JH et al. 1999; Holmes et al. 2003; Olunwa 1987). This finding is supported by our study.

In severely involved cerebral palsy child there are many factors which make optimal seating difficult. Therapist has few alternatives to provide for optimal position in seating device. So it is imperative to select alternatives by considering material, design and careful monitoring with respect to comfort, safety and function. Also the important aspect to highlight is the need of continuous follow-up and assessment of such devices in order to help in difficulties in their use. If the child's family is involved in the planning of the seating system and is aware of the aims of the seating team, it is much more likely that the chair will be used effectively.

\section{Acknowledgement}

"Our sincere thanks to Director, AIIPMR, Mumbai. We would like to express our gratitude towards the child's family for their support, Dept of Prosthetic and Orthotic, Dept. of Vocational Training workshop of AIIPMR for their valuable support".

\section{References}

[1] Lynda Hollett Hundertmark., (1985): Evaluating the adult with cerebral palsy for specialized adaptive seating. Physical Therapy, vol.65 No.2, 209-212.

[2] Kathleen Washington, Jean C Deitz, Owen R White and IIene S Schwartz.(2002): The effects of a Contoured foam seat on postural alignment and upper extremity function in infants with neuromotor impairments. Physical Therapy, 82; 1064-1076.

[3] Janet Bower Hulme., Kathleen Gallacher., James Walsh., Sherri Neisen., \& Debbie Waldron.(1987): Behavioral and Postural changes observed with use of adaptive seating by clients with multiple handicaps. Physical Therapy journal, vol. 67, No.7, 1060-1067.

[4] Linda McNamara., (2005): Postural management: Components of specialized seating equipment. Critical review of literature.

[5] Laura Neville., (2005): The fundamental principles of seating and positioning in children and young people with physical disabilities. Critical review of literature.

[6] Ling Sui Hui., et.al., (2011): Locally made Paediatric Rehabilitation and Seating systems for Cerebral palsy children in Sarawak. International journal of Public Health Research, 146-151.

[7] J. Martin Carlson., John Lonstein., Karen O.Beck., \& David C. Wilkie. Seating for children and young adults with cerebral palsy, (1987): Clinical Prosthetics and Orthotics, vol 11, No.7, 176 -198.

[8] Herman JH, Lange ML., (1999): Seating and positioning to manage spasticity after brain injury. Neurorehabilitation, Vol.12, No.2, 105-117.

[9] Holmes, AKJ, Michael SM, Thorpe SL \& Solomonidis SE., (2003): Management of scoliosis for the non-ambulant spastic cerebral palsy population - a biomechanical study .Clinical biomechanics, 18; 480-487.

[10] Olunwa Mafiana Nwaobi. Seating Orientatins and Upper extremity function in children with Cerebral palsy. Physical Therapy Journal 1987; 67 (8): 1209-1212.

\section{Volume 6 Issue 7, July 2017 www.ijsr.net}

